Article

\title{
Yeast Chemogenetic Screening as a Tool to Unravel the Antifungal Mode of Action of Two Selected Selenocyanates
}

\author{
Muhammad Sarfraz ${ }^{1,2}$, Muhammad Jawad Nasim ${ }^{2}{ }^{(D}$, Claus Jacob $^{2}$ and Martin C.H. Gruhlke ${ }^{1, *}$ \\ 1 Department of Plant Physiology, RWTH Aachen University, 52056 Aachen, Germany \\ 2 Division of Bioorganic Chemistry, School of Pharmacy, Saarland University, 66123 Saarbruecken, Germany \\ * Correspondence: Martin.Gruhlke@rwth-aachen.de; Tel.: +49-241-80-25812
}

Received: 22 July 2019; Accepted: 19 August 2019; Published: 6 September 2019

\begin{abstract}
During recent decades, selenium-containing compounds, as with the chemically similar sulfur-containing compounds, have gained considerable interest as cytotoxic and anticancer agents. Selenocyanates represent a well-established class of organic selenium compounds. These agents exhibit a wide range of biological activities. Classically, selenocyanates may cause an increase in the intracellular levels of reactive oxygen species (ROS) and exert cytotoxic activities, thus, acting as pro-oxidants. In this study, chemogenetic profiling was carried out to decipher the resistance mechanisms as central part of the antifungal mode of action against two selected selenocyanates. If a mutant line is less resistant against a compound compared to the wildtype, the gene deleted in that strain seems to be correlated with the resistance. Yeast mutants carrying gene deletions for specific redox-related protein function were employed in the chemogenetic screening. The results of screening reveal the hypersensitivity of mutants carrying deletions for glutathione pool and metabolism. To confirm the results, Arabidopsis mutants deficient in glutathione were subjected to various concentrations of selenocyanates to observe their effects on mutants and the wildtype. A significant dose dependent inhibition in Arabidopsis mutants compared to the wildtype confirmed the findings of the chemogenetic screening. The data suggest that the two representatives of organoselenium compounds cause oxidative stress in yeast cells and glutathione participates towards the development of resistance against the chemicals.
\end{abstract}

Keywords: selenocyanates; yeast mutants; Arabidopsis mutants; chemogenetic screening; oxidative stress; glutathione metabolism

\section{Introduction}

Selenium (Se) is a vital nutritional trace element involved in antioxidative metabolism with antitumor and chemo-preventive properties [1]. Se, being a chalcogen, exhibits a similar chemical behavior as sulfur, which is the central redox active element in biochemistry. Hence, Se, in some cases, can replace sulfur, as it is found in the amino acids, such as selenocysteine or selenomethionine. Chemical derivatives of selenium consist of organic compounds, like selenomethione and selenomethyl-selenocysteine, and inorganic compounds, such as selenite [2].

The modulation of the cellular redox-environment is an increasing target for compounds that are employed as antibiotic or selective targeting of cancer cells in chemotherapy. Sulfur containing compounds, including natural products, such as thiosulfinates or polysulfanes are well-established examples of agents affecting the cellular redox status, thus, exhibiting cytotoxic effects [3]. Also, selenium-containing compounds or Reactive Selenium Species (RSeS) can redox modulate the oxidative stress (OS) present in various cancer cells [4]. Se compounds are well-established redox modulators 
with increased selectivity for cancer cells [5]. These compounds can cause an increase in the oxidative stress in cancer cells, thus, acting as pro-oxidants, which seems to be responsible for the cytotoxic and antiproliferative activities of such RSeS [5]. Selenocyanates are selenium analogues of naturally occurring thiocyanates and constitute an important group of organoselenium compounds [6]. These compounds are versatile as they serve as precursor for the synthesis of numerous new organoselenium compounds, such as seleninic acids and diselenides in synthetic chemistry and as potent cytotoxic agents in biology [7]. Various selenocyanates were synthesized and have shown pronounced antimicrobial activity against multidrug resistant ESKAPE bacteria [8]. The naturally occurring and synthetic selenocyanates have shown efficacy against various cancers [9]. These compounds are able to produce superoxide, nitric oxide and other ROS via redox cycle [10]. Various mechanisms of action of selenium compounds have been proposed. In relation to anticarcinogenesis, these agents are transformed to various metabolites, such as methyl selenol $\left(\mathrm{CH}_{3} \mathrm{Se}^{-}\right)$and hydrogen selenide $\left(\mathrm{HSe}^{-}\right)$, acting as pro-oxidants. These metabolites increase ROS via redox cycling with glutathione (GSH) or the Trx/Grx systems producing ROS [11]. Glutathione (a tripeptide) performs a variety of functions in living organisms [12]. Glutathione interacts with ROS, thus, acting as antioxidant [13]. RSeS are also able to alter the intracellular redox balance by the oxidation of intracellular thiols [14]. Redox modification of thiols results in iron and calcium homeostasis [15], and ultimately may lead to the loss of biological function of proteins [16]. Another cytotoxic mode of action of these compounds involves the interaction of selenium with cell cycle which leads to apoptosis. For instance, methylselenide causes caspase-mediated apoptosis in G1 phase, while selenite is involved in the cell cycle arrest in S phase and results in caspase-independent apoptosis. Similarly, DNA damage can be caused by selenite treatment [17]. Prolonged treatment of normal and malignant tissues with selenium results in DNA damage [18] and such modifications may lead to DNA repair. An enhancement in selenite-induced growth impairment in yeast was observed in strains devoid of pathways of DNA repair [19]. Chromatin and/histone modifications are more recent novel mechanisms of action of organo-selenium compounds [20].

Literature reveals a marvelous amount of data concerning the anticancer activity of selenocyanates. However, to understand in more detail how these compounds exhibit an anticancer activity, it is hard to work with cell cultures. The detailed analysis of antifungal activity of various compounds against yeast cells is, therefore, an easy and reliable approach for a first idea for the understanding of other toxic properties, such as anticancer activities. To understand the mode of action and to characterize the promising target of cytotoxic compounds, the technique called chemogenetic profiling is exploited. This procedure employs the screening of mutant yeast strains with knocked out genes encoding specific proteins [21]. In the presence of a cytotoxic compound, the heterozygous diploid strain with gene deletion and the wildtype homozygous diploid yeast strain are allowed to grow, and subsequently, the growth inhibition shown by yeast strains when compared with the wildtype, points towards the drug target [22]. In response to the exposure to a cytotoxic compound, a library of diploid yeast strains devoid of one copy of different genes, leads to approximately partially expressed protein, and this technique refers to the haploinsufficiency. While interpreting the compound's unknown mechanism of action (MOA), the haploinsufficiency screening technique identifies the cellular targets, as well as the off-target mode of action (e.g., neuroleptic agents) [23]. Exploring the specific mode of action of various compounds represents a crucial task in the drug discovery and development. Yeast deletion collection comprising 21,000 haploid and 6000 diploid deletion strains of Saccharomyces cerevisiae is useful for identifying the mechanism of action and drug discovery [24]. The yeast, $S$. cerevisiae, is commonly employed and the reason to opt for it as a model organism is because of the good characterization of its genome and proteome, with approximately $45 \%$ gene homology with mammalian genes [23]. Yeast is a eukaryote and, hence, has a nucleus and other organelles, such as mitochondria, endoplasmic reticulum and vacuoles like in animals and plants. Yeast is more closely related to animals than plants at the molecular level [25]. Many pathways are conserved in evolution from yeast to mammals [26]. Yeast is also a good model for the molecular understanding of human 
diseases $[27,28]$. Approximately, 1200 mutants of heterozygous diploid yeast strains are available for scientific community from Euroscarf [29].

The present study involves the investigation of the role of glutathione and oxidative stress as the antifungal mode of action of selenocyanates by employing a combination of various assays. Chemogenetic profiling was carried out by utilizing a specific yeast mutant library deficient in genes coding for redox related protein function to confirm the specific role of glutathione [30]. In this study, we focused mainly on the redox-function of the selenocyanates, thus, we chose a sublibrary including the mutant strains compromised in genes related to redox-maintenance. The protective role of glutathione against selenocyanates was assessed by employing Arabidopsis seedling root growth assay. Arabidopsis is a multicellular organism and responds very sensitively to changes in glutathione homeostasis. This property makes it a suitable system to analyze the effects of selenocyanates on glutathione pool. The glutathione level determination in yeast also provided a glimpse into the antifungal mode of action of organoselenocyanates.

\section{Materials and Methods}

\subsection{General Procedure for the Synthesis of Selenocyanates}

The synthesis of the selenocyanates (Figure 1) was carried out as described previously in literature [8]. According to this procedure, alkyl halides $(10-20 \mathrm{mmol})$ were treated with $\mathrm{KSeCN}$ $(12-25 \mathrm{mmol})$ in the presence of ethanol $(10-20 \mathrm{~mL})$. The reaction mixture was refluxed for $6 \mathrm{~h}$ and the progress of the reaction was monitored periodically by thin layer chromatography (TLC). After the completion of the reaction, the inorganic salt was separated by filtration and the filtrate was boiled with charcoal which was subsequently filtered off. Filtrate was evaporated to obtain solid substance which was crystallized with ethanol to yield crystals of aromatic selenocyanates.

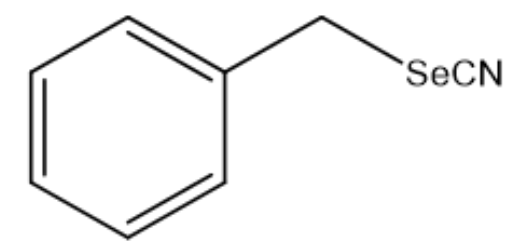

(selenocyanatomethyl)benzene

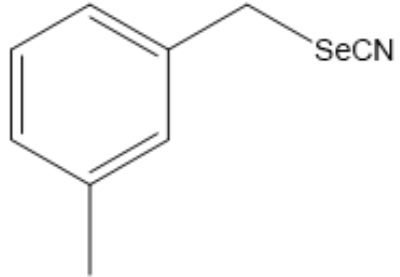

1-methyl-3-(selenocyanatomethyl)benzene

\section{Compound 1}

\section{Compound 2}

Figure 1. Chemical structures of selenocyanates employed in the selected chemogenetic profiling.

${ }^{1} \mathrm{H}$ NMR and ${ }^{13} \mathrm{C}$ NMR spectra were recorded on a Varian Mercury-VX $300 \mathrm{MHz}$ PFG instrument in DMSO- $d_{6}$ at ambient temperature using the solvent signal as an internal standard. The values of the chemical shifts are expressed in ppm and the coupling constants $(J)$ in Hz. Mass spectra were recorded on a UPLC-MS/MS system consisted of a Waters ACQUITY ${ }^{\circledR}$ UPLC $^{\circledR}$ (Waters Corporation, Milford, MA, USA) coupled to a Waters TQD mass spectrometer (electrospray ionization mode ESI-tandem quadrupole). The UPLC/MS purity of all the final compounds were confirmed to be higher than $95 \%$. Retention times $(t R)$ are given in min. Thin-layer chromatography was performed on pre-coated Merck silica gel $60 \mathrm{~F}_{254}$ aluminum sheets. The reactions at a fixed temperature were carried out using a magnetic stirrer with a contact thermometer Heidolph MR 2001. 


\subsection{Growth Media and Strains}

\subsubsection{YPD (Yeast Peptone Dextrose) Growth Medium}

$10 \mathrm{~g} / \mathrm{L}$ Yeast extract (Duchefa Biochemie, Haarlem, The Netherlands); 20 g/L Peptone (Duchefa Biochemie, Haarlem, The Netherlands); $20 \mathrm{~g} / \mathrm{L}$ Glucose (Duchefa Biochemie, Haarlem, The Netherlands); and for solid media, $15 \mathrm{~g} / \mathrm{L}$ of Agar-Agar, Kobe 1 (Carl-Roth, Karlsruhe, Germany), was added and the mixture was autoclaved. The YPD medium was used for yeast growth.

\subsubsection{CSM (Complete Supplement Medium) Growth Medium}

$6.9 \mathrm{~g} / \mathrm{L}$ Yeast Nitrogen Base (Formedium, Norfolk, UK); $0.8 \mathrm{~g} / \mathrm{L}$ Complete Supplement Mixture (CSM) Drop Out: Complete (Formedium, Norfolk, UK); 40 g/L Glucose (Duchefa Biochemie, Haarlem, The Netherlands), and for solid medium 15 g/L Agar-Agar, Kobe 1 (Carl-Roth, Karlsruhe, Germany) was added and the mixture was autoclaved. The CSM broth medium was employed for growth kinetics measurement while CSM agar was used for drop test, plate inhibition zone assay and streak test.

\subsubsection{Yeast Strains}

The S. cerevisiae strains used in this study were BY4742 (Mat $\alpha$; his $3 \Delta 1$; leu2 $\Delta 0$; lys $2 \Delta 0$; ura $3 \Delta 0$ ) and yeast mutants deleted for specific redox related protein function. A complete redox library consisting of selected yeast mutants deficient in specific protein function was screened (the list of mutants tested is given in Supplementary Table S1). The 11 mutants were found hypersensitive compared to wildtype (wt). The hypersensitive mutants YNL241C, YPL091W, YML007W, YGR209C and YHR183W, lacked genes encoding the respective proteins, which play a role in glutathione metabolism and provide resistance against oxidative stress. These mutants were studied further in detail.

\subsection{Measurements of Yeast Growth Kinetics for Quantitative Identification of Hypersensitive Strains}

The hypersensitive yeast strains were identified by measuring the growth kinetics in the presence of test compound and in the absence of it. For quantitative identification of hypersensitive strains, a library of selected knockout yeast mutants was purchased from Euroscarf and re-arrayed into 96 well plates in $15 \%$ glycerol to produce a library of four plates which were then stored at $-80{ }^{\circ} \mathrm{C}$. These mutants were then screened against compounds. The effect of compounds on the growth kinetics of different yeast strains was determined as follows: Selected yeast mutants and wt cultures were grown overnight $(50 \mathrm{~mL}$ YPD inoculated with a few colonies in a $250 \mathrm{~mL}$ Erlenmeyer flask, shaken at $220 \mathrm{rpm}$ and $28^{\circ} \mathrm{C}$ ) and were diluted to an $\mathrm{OD}_{600}$ of 0.9 (measured with a DU $530 \mathrm{UV}$-Visible spectrophotometer (Beckman Coulter $\mathrm{GmbH}$, Krefeld, Germany). Then, $158 \mu \mathrm{L}$ medium was mixed with $7 \mu \mathrm{L}$ diluted culture per well of polystyrene flat base 96 well plate by using a 12 channels pipette. Compound was added to each well to achieve a final concentration of $15 \mu \mathrm{M}$. The untreated wells contained culture and medium for growth only. The plate was shaken at $28^{\circ} \mathrm{C}$ and the OD at $600 \mathrm{~nm}$ was measured continuously overnight in a plate reader (Plate reader Tristar ${ }^{2}$ LB 942 Multimode Reader by Berthold Technologies GmbH \& Co. KG, Bad Wildbad, Germany) [30].

\subsection{Drop Test}

CSM medium with agar was heated to $55^{\circ} \mathrm{C}$ and transferred to $50 \mathrm{~mL}$ falcon tube (Thermo Fisher Scientific CO, Waltham, MA, USA). Compounds were added to the falcon tube to achieve the required concentrations $(2.5$ and $5 \mu \mathrm{M})$. The falcon tube was closed and inverted in such a way to mix the compound homogeneously. The media was then poured carefully to a Petri-dish $(10 \times 10 \times 2 \mathrm{~cm})$. Different overnight yeast cultures were adjusted to $\mathrm{OD}_{600}$ of 1 (measured with a spectrophotometer DU 530 by Beckman Coulter GmbH, Krefeld, Germany) and then subsequently diluted to $10^{\text {n }}$ dilutions with sterile water. Then, these serial dilutions were pipetted onto plates containing the desired 
concentrations of compounds in CSM. Controls were spotted onto plates containing growth medium only. The plates were incubated at $28^{\circ} \mathrm{C}$ for $48 \mathrm{~h}$ [29].

\subsection{Plate Inhibition Zone Assay}

Overnight cultures of BY4742 and yeast mutants were grown in Yeast Peptone Dextrose (YPD) medium under optimal conditions $\left(220 \mathrm{rpm}, 28^{\circ} \mathrm{C}\right)$, diluted to about $\mathrm{OD}_{600}$ of 0.1 and further grown to $\mathrm{OD}_{600}$ of 0.5 . Temperature of $\mathrm{CSM}$ agar was equilibrated in the water bath to $50^{\circ} \mathrm{C}$. The $50 \mu \mathrm{L}$ of culture was added to $10 \mathrm{~mL}$ of medium, mixed in a falcon tube and poured into a Petri-dish with a $9 \mathrm{~cm}$ diameter. Upon solidification, holes were punched out employing a cork borer (6 mm diameter). Each hole was filled with $20 \mu \mathrm{L}$ of compound solution $(8,4$ and $2 \mathrm{mM})$. Plates were incubated at $28^{\circ} \mathrm{C}$ for $20 \mathrm{~h}$ for complete growth. The diameter of the inhibition zone was measured, and plates were photographed.

\subsection{Streak Test}

The $10 \mathrm{~mL}$ of molten CSM medium at $50^{\circ} \mathrm{C}$ was poured to Petri plate. After the solidification of medium, a hole was cut out in the center of Petri plate with a $6 \mathrm{~mm}$ diameter corkborer. An overnight growing colony of each of the test yeast, wt and mutants, was picked with an inoculating loop. Each colony was suspended in $100 \mu \mathrm{L}$ of CSM broth medium, vortexed for $10 \mathrm{~s}$ and a loopful was streaked away radially from the central hole towards the edge of the petri plate. The $20 \mu \mathrm{L}$ of selenocyanate solution was pipetted into the well. The plates were incubated for $48 \mathrm{~h}$ at $28{ }^{\circ} \mathrm{C}$. The distance between the growing streak of yeast and the center was measured and documented.

\subsection{Arabidopsis Seedling Root Assay}

Arabidopsis seedling root assay was performed as described in literature [30]. Sterilized Arabidopsis thaliana seeds Col-0, gr1 (At3g24170) and pad2-1 (At5g66140) were sown on sterile filter papers and placed on Murashige and Skoog (MS) solid medium. According to root gravitropism, the petri plates were tilted to an angle of approximately $70^{\circ}$ to ensure root growth. After three days of cultivation, each filter paper was transferred to MS medium containing different concentrations of selenocyanates. After three days of the treatment, seedlings were photographed, and the root length was measured [30].

\subsection{Glutathione Determination}

A standard enzymatic recycling assay was employed to measure glutathione level on the basis of glutathione reductase (GR) [31], and the procedure was adjusted as described [32]. Reaction involved the oxidation of GSH to GSSG by 5,5'-dithiobis-(2-nitrobenzoic acid) (DTNB; Merck, Germany) whilst in the presence of GR, it was reduced by NADPH (AppliChem, Germany). The rate of formation of 2-nitro-5-thiobenzoic acid was measured at $412 \mathrm{~nm}$ and the total level of glutathione was determined from a standard curve formed by using GSH (AppliChem, Germany). The prime principle of the assay involves the detection of GSSG levels by exploiting 2-vinylpyridine (purchased from Sigma, Germany) in order to remove GSH from GSSG/2GSH couple [31]. To standardize the system, standard curves were prepared with GSSG and GSH purchased from AppliChem and GR from Sigma (E 3664). A culture of BY4742 $\left(\mathrm{OD}_{600}\right.$ 0.4) was allowed to grow overnight followed by the addition of test compound to a final concentration of $1 \mathrm{mM}$, and it was allowed to rest for $30 \mathrm{~min}$. The reaction mixture was subsequently centrifuged at $4330 \times g$ for $10 \mathrm{~min}$ at $25^{\circ} \mathrm{C}$ to collect the cells and then packed cell volume was measured. Centrifugation was carried out to wash the cells twice in $43 \mathrm{mM}$ phosphate buffer ( $\mathrm{pH} 7.5$ ) with $6.3 \mathrm{mM}$ EDTA. Following resuspension of pellets in $1 \mathrm{~mL}$ buffer, approximately $200 \mu \mathrm{L}$ of 0.2 -mm-diameter glass beads were added. These were, then, vortexed for $3 \times 1 \mathrm{~min}$ to break the cells, allowed to cool on ice and finally centrifuged for $1 \mathrm{~min}$ at $15,800 \times g$. In order to determine the GSSG and GSH levels, aliquots of the supernatant were prepared as mentioned previously [31]. The constituents of the reaction mixture consisted of $12.5 \mu \mathrm{L}$ supernatant, $5 \mu \mathrm{L}$ GR $\left(20\right.$ units $\left.\mathrm{mL}^{-1}\right)$, $50 \mu \mathrm{L} 6 \mathrm{mM}$ DTNB and $350 \mu \mathrm{L} 0.3 \mathrm{mM}$ NADPH. All of these solutions were prepared with phosphate 
buffer. Water was added to the reaction mixture to make the final volume of $750 \mu \mathrm{L}$ and the final concentration of phosphate buffer was adjusted to $80 \mathrm{mM}$ with $3.5 \mathrm{mM}$ EDTA. To determine GSH and GSSG cell content, the total quantity in supernatant was considered as their concentration in packed cell volume while assuming the condition of the cell as: $15 \%$ volume occupied by cell walls and $20 \%$ of the volume was considered to be the vacuole; either cells contained a vacuole or were devoid of it [33], when estimating the maximum and minimum levels of GSH levels.

\subsection{Statistical Analysis}

All data (plate inhibition zone assay, streak test and Arabidopsis seedling root assay) were expressed as the standard error of the mean $( \pm$ SEM). The experiments were repeated in triplicate three times $(n=9)$ on three different occasions. Data comparisons were performed using one-way analysis of variance (ANOVA), and analysis was carried out by the Bonferroni post hoc test. GraphPad Prism (Version 5.03, GraphPad Software, San Diego, CA, USA) was used for data analysis and to generate charts. Normal distribution of each data set was represented by \pm SEM. Statistical significance was set at ${ }^{*} p<0.05,{ }^{* *} p<0.01$, and ${ }^{* * *} p<0.001$.

\section{Results and Discussion}

Chemogenetic profiling was carried out to identify the mode of action of two compounds with inhibitory activity against $S$. cerevisiae. Overall, the results presented here, as a part of the study, indicate the protective role of glutathione against selenium-containing compounds. The increase in oxidative stress has also been implicated as a pivotal mechanism in the microbial growth inhibition in the presence of selenium compounds. Chemogenetic profiling with selected yeast mutants resulted in the inhibition of growth of mutants deficient in genes coding for glutathione metabolism and oxidative stress tolerance proteins. Arabidopsis seedling root assay was also performed to see the effects of various concentrations of selenocyanates on Arabidopsis mutants deficient in glutathione. The greater inhibition of mutants with reduced levels of glutathione compared to wt in this assay confirms the findings of chemogenetic profiling. To support the results of aforementioned assays, glutathione levels were determined in yeast cells after treatment with selenocyanates. The cells without treatment (control group) exhibited higher levels of glutathione in comparison to the treated cells. These findings refer to the protective role of glutathione against selenium compounds. These results also hint towards the resistance provided by glutathione against various chemicals. Plate inhibition zone assay and streak test have been employed to get the additional information about the sensitivity of mutants compared to $w t$ in different assays. The higher sensitivity of mutants in relation to wt supports the findings of chemogenetic profiling.

\subsection{Chemogenetic Screening}

Chemogenetic profiling is a technique based on screening a library of selected yeast strains that are each deleted for one particular gene coding for specific protein. This procedure is used to identify the potential targets and mode of action of cytotoxic compounds [21,34-36]. Various yeast mutants with gene deletions coding for a special protein function are available which can be employed in chemogenetic screening studies. These studies provide a glimpse into the possible mode of action of test compounds by investigating the divergent sensitivities of the wildtype and different mutants against these agents. In this screening, the sensitivity of heterozygous diploid strain with a knockout gene is compared to wildtype in the presence of test compound. If the mutant lacks gene providing resistance, then that mutant will grow less compared to wildtype and this phenomenon is called haploinsufficiency profiling [23]. Chemogenetic screening of selected yeast mutants was carried out independently by employing $15 \mu \mathrm{M}$ of selenocyanates to decipher their mode of action. The mutants and wildtype (wt) BY4742 were tested by measuring the growth curves overnight in the presence and absence of compound. This screening resulted in the hypersensitivity of yeast mutant strains compared to wt. 


\subsection{Quantitative Identification of 11 Hypersensitive Strains}

Chemogenetic screening provides an additional advantage of measuring the growth kinetics over constant intervals of time [29]. As many heterozygous mutants grow slowly in culture medium, it is necessary to compare the growth kinetics of treated and untreated mutants and wildtype [22].

S. cerevisiae mutants lacking specific protein function were employed to assess the hypersensitive strains compared to wildtype. In the present study, 11 yeast mutants were recognized as hypersensitive compared to the untreated strains (Table 1). Mutants $\Delta y a p 1, \Delta g l r 1, \Delta z w f 1, \Delta \operatorname{tr} x 2$ and $\Delta g n d 1$ were then studied in more detail. These five yeast mutants were chosen for detailed analysis because these mutants lack genes coding for proteins implicated in glutathione metabolism, and proteins for oxidative stress tolerance. These mutants are deficient in genes sharing a common pathway. The other mutants hypersensitive to selenocyanates might also point towards the role of proteins other than those of glutathione metabolism and oxidative stress tolerance. The ability of wildtype (wt) BY4742 cells to grow in the presence of selenocyanate was compared with the ability of $\Delta y a p 1, \Delta g l r 1, \Delta z w f 1$, $\Delta g n d 1$ and $\Delta t r x 2$ yeast mutants.

Table 1. Names and functions of genes mutated in strains showing hypersensitivity as compared to the wildtype against compounds $\mathbf{1}$ and 2.

\begin{tabular}{ccc}
\hline ORF & Gene & Biological/Molecular Function \\
\hline YNL241C & ZWF1 & glucose-6-phosphate dehydrogenase activity \\
YML007W & YP1 & DNA-binding transcription factor activity \\
YPL091W & GLR1 & glutathione-disulfide reductase activity \\
YGR209C & TRX2 & disulfide oxidoreductase activity \\
YHR183W & GND1 & phosphogluconate dehydrogenase (decarboxylating) activity \\
YOR375C & GDH1 & glutamate dehydrogenase (NADP+) activity \\
YDL085W & NDE2 & NADH dehydrogenase activity \\
YDR197W & CBS2 & translation regulator activity \\
YR 009C & TDH2 & glyceraldehyde-3-phosphate dehydrogenase (NAD+) activity \\
YGR234W & YHB1 & nitric oxide reductase activity \\
YML056C & IMD4 & IMP dehydrogenase activity \\
\hline
\end{tabular}

The redox controlled transcription factor Yap1p plays central role in the regulation of the oxidative stress response in yeast [37]. Yap1 regulates the expression of numerous oxidative stress tolerance, glutathione metabolism and detoxifying genes, such as GSH1, GSH2, TRX2 and GLR1 $[38,39]$. Glr1p reduces GSSG to GSH by utilizing NADPH. Trx2p is the main thioredoxin in yeast which reduces glutathiolated proteins (PSSG) and disulfides (PSSP) back to thiols utilizing NADPH-dependent thioredoxin reductases [40]. NADPH is predominantly produced by glucose-6-phosphate dehydrogenase (Zwf1p) and 6-phosphogluconate dehydrogenase (Gnd1p) in the oxidative pentose phosphate pathway (PPP) [30]. Thus, these mutants point towards the glutathione metabolism as common mode of action of two selenocyanates.

As a precondition, the treatment of yeast with compound in question must cause the inhibition of growth. Figure 2 shows the growth inhibition of BY4742 against different concentrations of selenocyanates. The two compounds inhibited the growth of wildtype (BY4742) in shake cultures in concentration dependent manner. Compound 2 completely inhibited the growth of wt at concentration $\geq 20 \mu \mathrm{M}$. However, compound 1 exhibited maximum toxicity at concentration of $30 \mu \mathrm{M}$. These results reveal the involvement of genes required for specific functions; e.g., glutathione metabolism and oxidative stress resistance. 


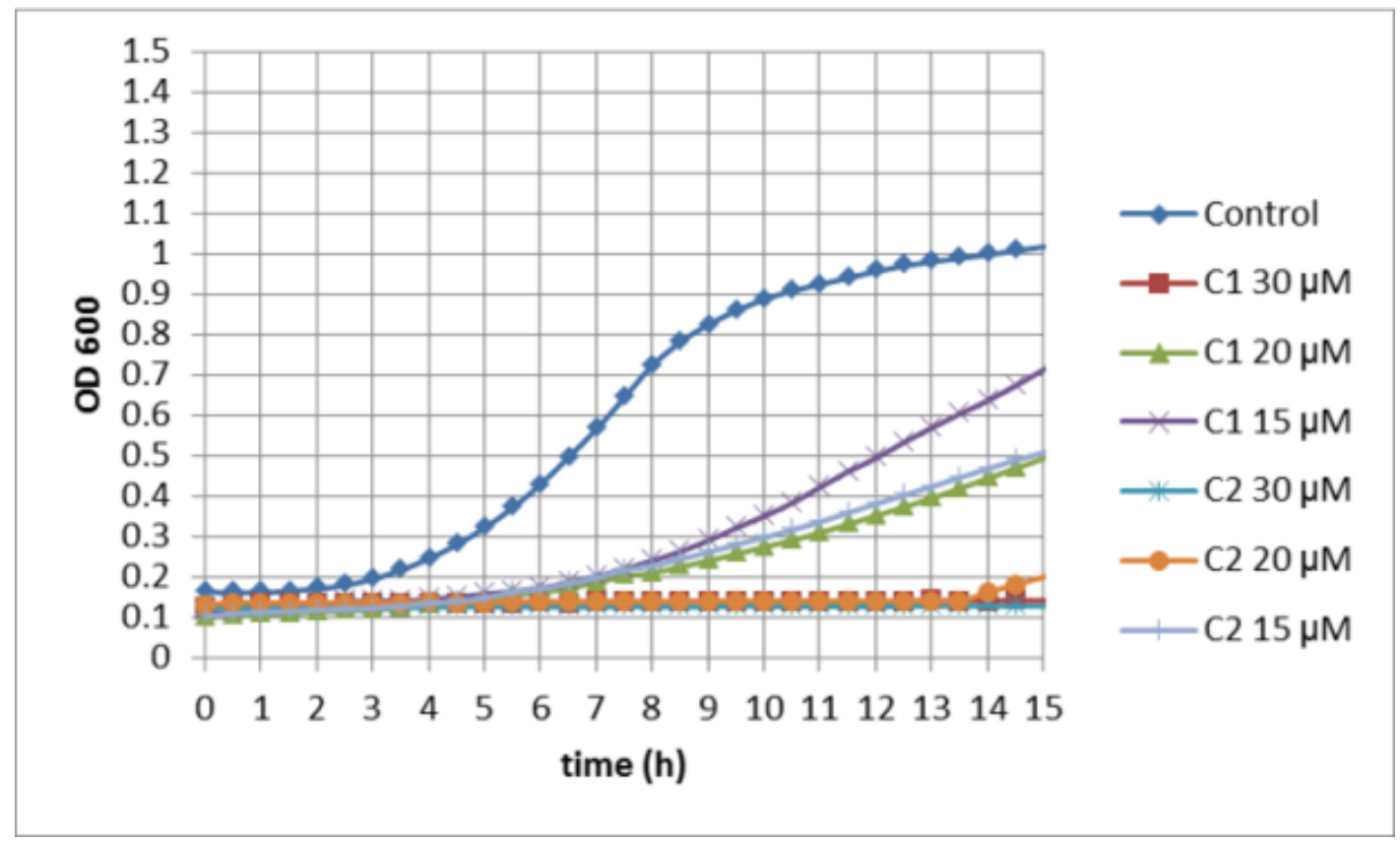

Figure 2. Effects of various concentrations of two selenocyanates on the growth in shake culture of wt BY4742. The experiment was carried out in triplicates and repeated twice with similar results. C1-Compound $\mathbf{1}$ and $\mathbf{C} 2-$ Compound 2.

Compared to drop test, where cells are spotted onto plates containing a compound or during stationary culture conditions in the minimum bactericidal concentration (MBC) and the minimum inhibitory concentration (MIC) tests, cells grow more vigorously and tolerate higher concentrations of antifungals in shake cultures [30]. Figure 3 shows a representative plot chosen from three replicates. The growth of BY4742 wildtype and the mutants in controls was also similar, presenting no variation in the timing of the start of exponential growth, the rate of growth or end point cell titer reached after $18 \mathrm{~h}$. Compound 1 inhibited the growth of wt and mutants and there was greater difference in growth between wt and mutants. Compound 2 at concentration of $15 \mu \mathrm{M}$ completely inhibited the growth of mutants. Compound 2 also exhibited a greater decrease in the growth of wt as compared to compound 1. The greater inhibition of $\Delta y a p 1$, deficient in oxidative stress tolerance proteins, compared to wt in the presence of test compound, identifies the role of oxidative stress in yeast cells inhibition and/or death after treatment with selected selenocyanates. Similarly, the inhibition of $\Delta g l r 1$ and $\Delta t r x 2$ deficient in GSH confirms the role of glutathione in cells protection against the test compounds. There is also growth inhibition of mutants $\Delta z w f 1$ and $\Delta g n d 1$ lacking proteins producing NADPH required for GSH production. Thus, these findings unravel the central role of GSH and protein thiol oxidation as mode of action of selenocyanates.

To summarize the results of the chemogenetic profiling, the observation that the mutants were generally more sensitive to selenocyanates than the wt suggests that the selenocyanates are targeting the cellular GSH pool and GSH metabolism, as well as resulting in protein thiol oxidation [41,42].

The significance of the Zwflp and Gnd1p effects are clear, because these enzymes are the chief source of NADPH required for Glr1p for the reduction of GSSG to GSH and Trx2p activity via thioredoxin reductases, utilizing NADPH [43]. Allicin (diallylthiosulfinate), for instance, exhibits similar mechanism of action and was shown to oxidize critical cysteines in Yap1p [38]. The mutants $\Delta y a p 1$ and $\Delta g l r 1$ also demonstrated hypersensitivity towards allicin and thiosulfinate analogues of allicin [30]. Dipyridyl disulfide (DPS) is highly reactive thiol oxidant and very toxic to yeast, as it also targets the glutathione pool and metabolism [44]. Thus, selenocyanates exhibit antimicrobial activities by a similar mode of action as allicin and DPS. 

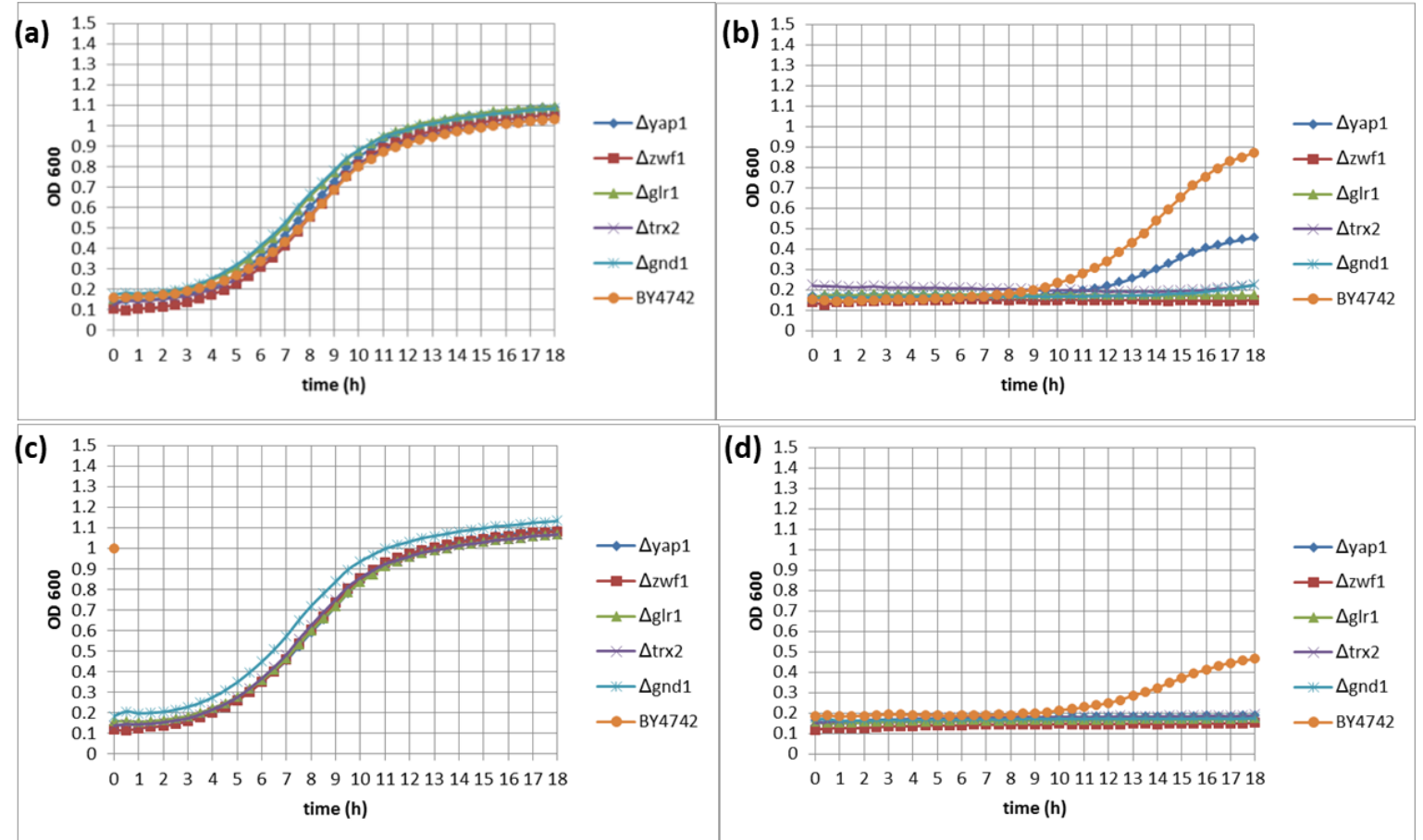

Figure 3. Effects of selenocyanates on the growth in shake culture of wt BY4742 and $\Delta y a p 1, \Delta g l r 1$, $\Delta z w f 1, \Delta g n d 1$ and $\Delta t r x 2$ mutant yeast cells in complete supplement medium (CSM). (a,c) CSM alone (control), (b) $15 \mu \mathrm{M}$ of Compound 1, and (d) $15 \mu \mathrm{M}$ of Compound 2. The experiments were repeated twice (growth curves were measured in triplicates) with similar results.

\subsection{Activity of Selenocyanates in Drop Test}

The drop test is an efficient standard technique for quantifying the activities of test substances on yeast. In this method, the test compound at a given concentration is incorporated into molten agar medium and poured immediately into plates. A total of $10 \mu \mathrm{L}$ of a 10th dilution series of a freshly growing yeast culture is spotted onto medium containing the test compound. After incubation for $48 \mathrm{~h}$ at $28^{\circ} \mathrm{C}$, individual colonies can be counted and compared in the plates with or without the compound. A fixed concentration of test substance is employed in drop test and serial dilutions of microbial culture are tested. Figure 4 shows the comparison of the yeast mutants and wildtype on plates in the presence and absence of compound.

In the absence of compound in the medium, the wt and yeast mutants grew equally well down to the $10^{-5}$ fold dilution. Compound 1 at a concentration of $5 \mu \mathrm{M}$ inhibited the wildtype and mutants demonstrating a greater inhibition in $\Delta z w f 1, \Delta y a p 1, \Delta g l r 1$ and slightly in $\Delta g n d 1$ and $\Delta t r x 2$ cells. Compound $\mathbf{2}$ inhibited the growth of wt to greater extent as compared to compound $\mathbf{1}$. The mutants $\Delta z w f 1$ and $\Delta g l r 1$ were found to be the most sensitive to compound 2. These findings confirm the results of chemogenetic profiling and reveal considerable toxicity of selenocyanates particularly of compound 2 towards yeast. The Yap1 is a member of AP-1 family of transcription factors and in response to oxidative stress, Yap1 activates antioxidant genes [45]. Yap1 regulates the antioxidant genes, such as Glr1, Gsh1, Trx1 and Trx2 [39]. The transcriptional activity of Yap1 is governed by redox dependent control at subcellular level [46]. The C-terminal domain contains a nuclear export signal (NES) while $\mathrm{N}$-terminal has nuclear localization signal NLS [47]. Yap1 is exported via Crm1p from nucleus in the absence of oxidative stress [48]. However, during oxidative stress, Yap1 nuclear export is hampered due to conformational change. It results in the increased transcriptional activity of Yap1 [49].

The hypersensitivity of Yap1, towards the selenocyanates under investigation, explains the increase in oxidative stress. The similar mode of action has been proposed for resveratrol which is a polyphenol and produces oxidative stress at lower concentration [50]. Yap1 cells are sensitive to 
resveratrol which activates the transcriptional activity of Yap1 [51]. Allicin also modifies thiols by oxidation and has also been shown to activate Yap1 [38].

\begin{tabular}{|c|c|c|}
\hline Control & Compound 1 & Compound 2 \\
\hline $\begin{array}{llllll}10^{0} & 10^{-1} & 10^{-2} & 10^{-3} & 10^{-4} & 10^{-5} \\
\end{array}$ & 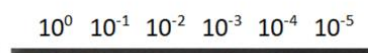 & $\begin{array}{llllll}10^{0} & 10^{-1} & 10^{-2} & 10^{-3} & 10^{-4} & 10^{-5}\end{array}$ \\
\hline BY4742 00000 繁 & 0000. & $000 \%$ \\
\hline$\Delta z w f 1 \bigcirc \bigcirc 00$ 綃 & 000 & 000 \\
\hline syap1 00000 & 000 & 0000 \\
\hline$\Delta g l r 1000000$ & 000 & 000 \\
\hline$\Delta \operatorname{trx} 2000000$ & $000^{\circ} 0$ & 000 \\
\hline 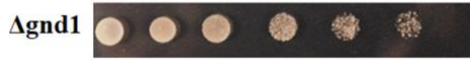 & $000 \%$ & 000 \\
\hline
\end{tabular}

Figure 4. Drop test of Saccharomyces cerevisiae cells on CSM medium containing $5 \mu \mathrm{M}$ of test compound. The wt BY4742 was compared with the mutants. Drops $(10 \mu \mathrm{L})$ of serial dilutions up to $10^{-5}$ were plated out. In the control, both wt and mutant cells behaved similarly and grew down to the $10^{-5}$ dilution. In the drop test, $10 \mu \mathrm{L}$ of $10^{-5}$ fold serial dilutions were spotted onto medium containing $5 \mu \mathrm{M}$ of the test compound. The control plate comprised of medium only. The ability of wildtype (wt) BY4742 cells to grow in the presence of selenocyanates was compared with that of $\Delta y a p 1, \Delta g l r 1 . \Delta g n d 1$, $\Delta t r x 2$ and $\Delta z w f 1$ yeast mutants.

These results also highlight the pivotal role of oxidative stress and GSH metabolism as the underlying mode(s) of action of selenocyanates. Further studies are needed to explore the additional mechanisms responsible for the antimicrobial activity of selenocyanates, probably beyond their redox-activity.

\subsection{Plate Inhibition Zone Assay}

The antifungal effect of selenium compounds can be investigated by monitoring the growth of wt and mutants. Different concentrations of test compound are employed to evaluate whether there is concentration dependent decrease in the growth of wt and mutants. In this procedure, yeast-seeded agar was employed to assess the sensitivity of yeast strains. A suspension of yeast culture was mixed in agar medium at $50{ }^{\circ} \mathrm{C}$ and poured with the agar immediately into petri plate. After solidification of agar, holes were cut and $20 \mu \mathrm{L}$ of respective concentration of the test substance was added to each well. The plates were incubated at $28^{\circ} \mathrm{C}$ for $20 \mathrm{~h}$ which enabled the yeast cells to grow widely from the wells.

Figure 5 represents the yeast mutants inhibited by the selenocyanates. These yeast mutants are deficient in genes playing a pivotal role in the glutathione metabolism. The compounds inhibit yap1 and glr1, thus, blocking the synthesis of GSH from GSSG. Similarly, selenocyanates cause a decrease in the production of NADPH required for GSH synthesis by inhibiting the mutants $\Delta z w f 1, \Delta g n d 1$ and $\Delta t r x 2$. This explains the antifungal action of selenocyanates.

Figure 6 shows the effect of $20 \mu \mathrm{L}$ of selenocyanates at concentrations of 2,4 and $8 \mathrm{mM}$, respectively. Both of the compounds diffused well into the agar and exhibited antifungal activity with clear zones of inhibition in concentration dependent manner. Compound 2, however, exhibited higher antifungal activity as compared to compound $\mathbf{1}$, as observed in other assays. Moreover, mutants also exhibited greater zones of inhibition in comparison to wt. These findings are in accordance with those of chemogenetic profiling, which also demonstrated that mutants are more sensitive to selenocyanates compared to wt. This assay provides insights into the higher sensitivity/toxicity of mutants inhibited in chemogenetic screening.

Each mutant was compared with the wt at each concentration. Compound $\mathbf{1}$ inhibited each mutant to a higher degree as compared to wt. Higher zones of inhibition were observed for all the 
mutants. Compound 2 exhibited higher toxicity to mutants and wt in comparison to compound $\mathbf{1}$. However, wt was inhibited to a lesser extent with reference to mutant strains.

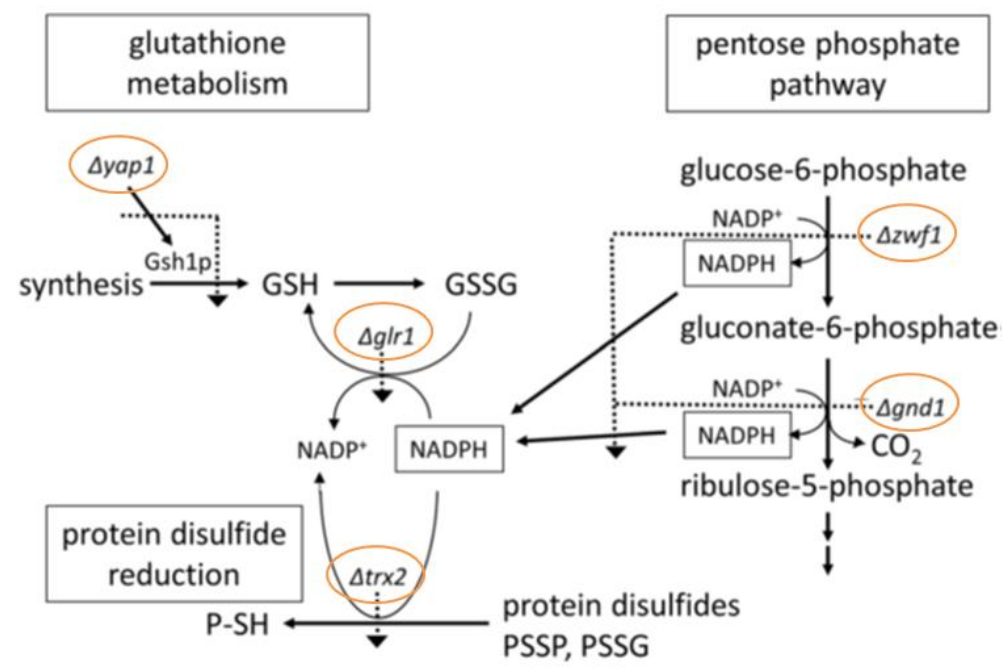

Figure 5. Schematic representation of the mutants inhibited by the selenocyanates. It also shows the activities of yeast mutants; $\Delta$ yap1 (GSH synthesis and GSSG reduction), either directly ( $\Delta g l r 1$ ), or by blocking the production of $\Delta z w f 1$ and $\Delta g n d 1$ (NADPH reducing equivalents) or by suppressing the NADPH-dependent reduction of protein disulfides ( $\Delta t r x 2$, indirectly $\Delta z w f 1$ and $\Delta g n d 1)$. The encircled mutants are the targets of selenocyanates showing hypersensitivity. Dotted lines show the metabolic lesions caused by the deletion mutants (modified from [30]).

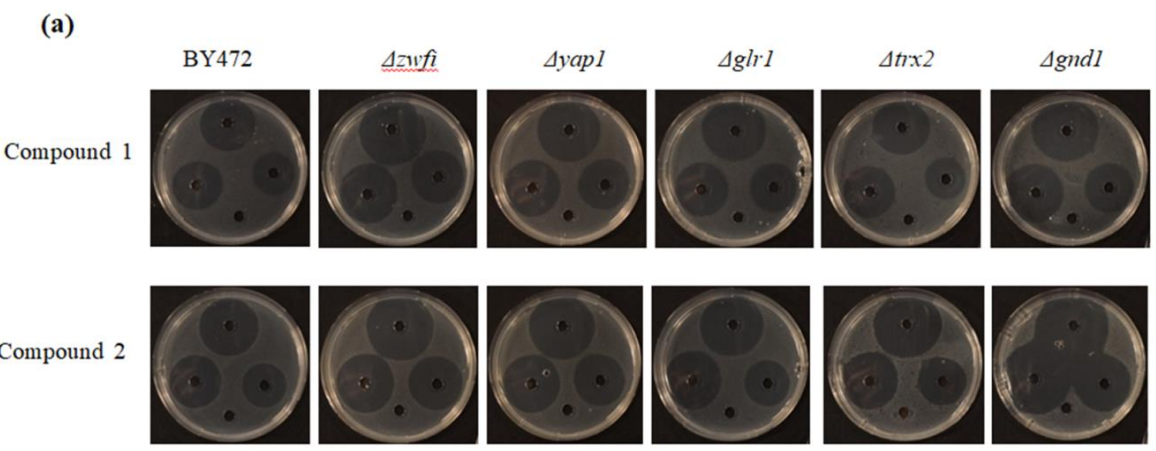

(b)
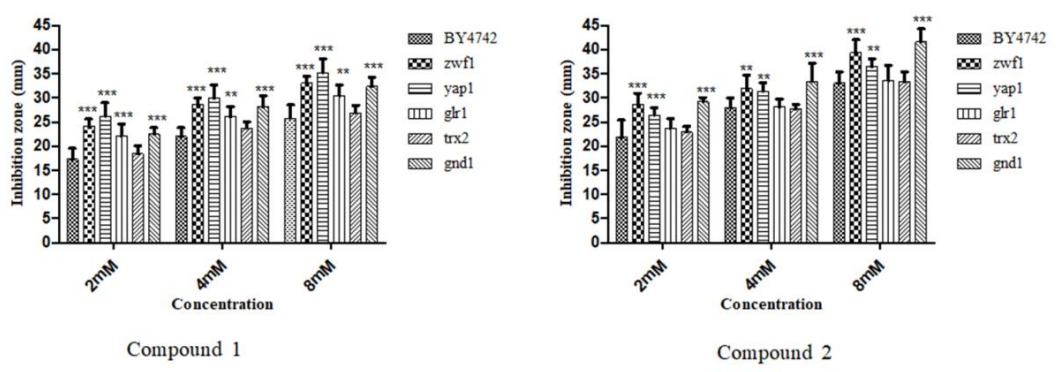

Figure 6. Plate inhibition zone assay showing the antifungal activity of two selenocyanates against yeast wt and mutants. (a) The representative pictures of inhibition zones of yeast mutants and wt (BY4742). Cells were incorporated into $50{ }^{\circ} \mathrm{C}$ warm agar and poured into a Petri plate. The upper well contained $20 \mu \mathrm{L}$ of $8 \mathrm{mM}$ solution, the hole at the left side of each Petri dish contained $20 \mu \mathrm{L}$ of 4 $\mathrm{mM}$ solution and the hole at the right side of the Petri dish contained $20 \mu \mathrm{L}$ of $2 \mathrm{mM}$ solution of each compound tested. The lower hole contained $20 \mu \mathrm{L}$ of $5 \%$ DMSO. (b) The diameter of inhibition zone was measured. Error bars show standard deviation about the mean, $n=9$. Values represent means \pm S.D. ${ }^{* *} p<0.01$ and ${ }^{* * *} p<0.001$. 


\subsection{Streak Test}

The streak test is the variant of plate inhibition zone assay. This assay was carried out to confirm the hypersensitivity of mutants compared to $\mathrm{wt}$, though this test did not provide clear demarcation between the sensitivities of various tested mutants towards the selenocyanates. A single well was punched in the center of the plate and yeast cells were streaked away from the center to the edge of the plate. A total of $20 \mu \mathrm{L}$ of the corresponding concentration of test compound was added to the well. Figure 7 shows the inhibitory effect of selenocyanates on yeast wt and mutants. This test works better in case of bacteria but for yeast the results are not so productive. Each of test compounds has inhibited the yeast cells but there is no clear demarcation between the growth inhibition of wt and mutants. Therefore, it is recommended to use different tests. It was observed that in case of compound $\mathbf{1}, \mathrm{wt}$ grew up to the well, but all the other mutants were inhibited to the same extent. However, compound 2 inhibited the wt but growth inhibition was higher for mutants.

(a)

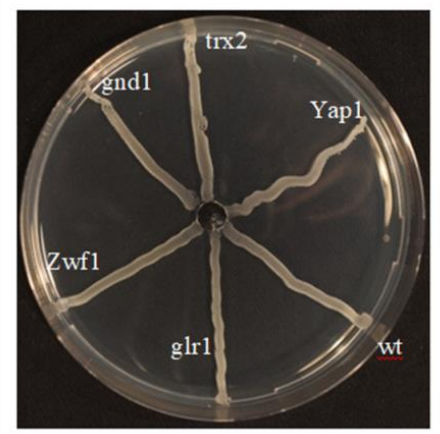

(b)

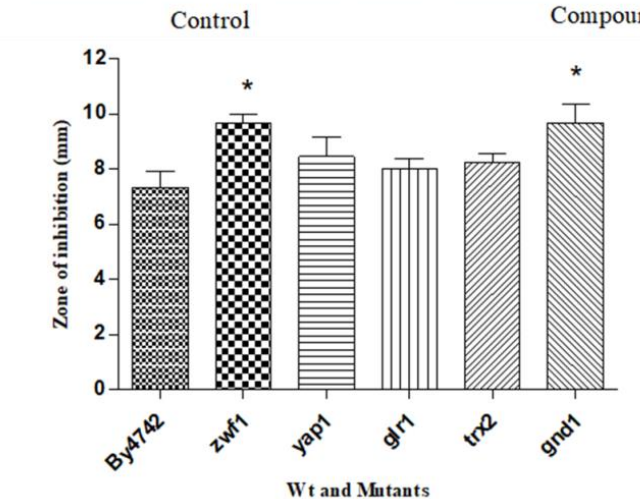

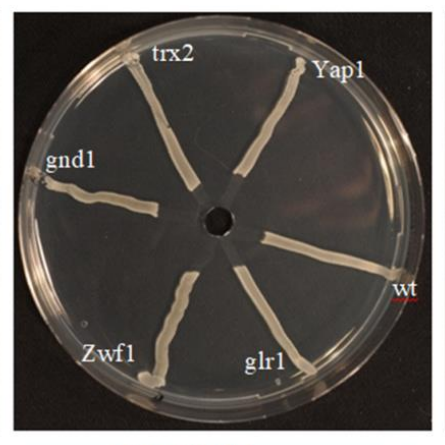

ompound 1

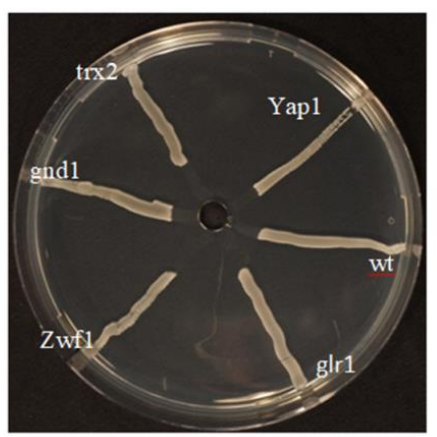

Compound 2

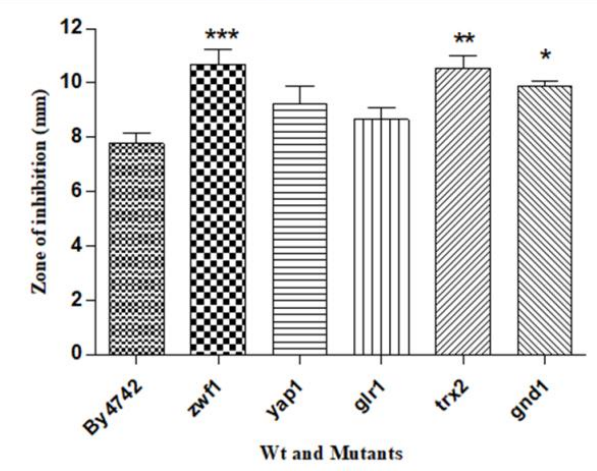

Figure 7. The streak test technique for comparing the inhibition of wt and different mutants by the compounds. This assay does not give such a clear result as the plate inhibition zone test (Figure 5), however wt and several mutants can be tested on a single Petri plate. (a) In the example shown, $20 \mu \mathrm{L}$ of $1 \mathrm{mM}$ of test compound was pipetted into the central well. (b) Graphs showing the zones of inhibition of wt and mutants treated with compound 1 (Graph on the left side) and compound 2 (Graph on the right side) Values represent mean \pm S.D. ${ }^{*} p<0.05,{ }^{* *} p<0.01$ and ${ }^{* * *} p<0.001$. The growth inhibition zone of mutants was compared with that of wt after treatment with selenocyanates.

\subsection{Effect of Selenocyanates on Arabidopsis Seedling Root Growth}

This assay was included in the study to unravel the effects of selenocyanates in a multicellular model organism, such as Arabidopsis thaliana along with unicellular yeast. A. thaliana mutants, deficient in glutathione, are available and commonly employed to evaluate the effects of compounds targeting the glutathione pool and metabolism. The inhibition of glutathione deficient mutants in this assay confirms the results of chemogenetic screening in a multicellular organism. The effects of selenocyanates on the growth of Arabidopsis seedling roots were observed by employing wildtype, as well as mutants deficient in glutathione. employed. A threshold concentration of glutathione is an important prerequisite 
for root growth [52]. Seeds were allowed to grow for three days before placing them on medium containing the corresponding concentration of the respective selenocyanate and after three days of continual exposure, root length was measured [30]. Arabidopsis Col-0 wt and gr1 and pad2 mutants in the Col-0 background were employed in the study. The gr1 mutant line is a knockout mutant of glutathione reductase and cannot reduce GSSG back to GSH. So, it has a higher proportion of GSSG in the glutathione pool [53]. The pad2 line is mutated in the glutamate cysteine ligase gene and contains only approximately $20 \%$ of the GSH level as compared to wt [54]. The mutants pad 2 and gr1, compromised respectively in GSH synthesis and GSSG reduction, are more sensitive than the Col-0 wildtype upon treatment with selenocyanates. Thus, the root growth was impaired in these mutants with reference to wt (Figure 8). The enhanced sensitivity of mutants, deficient in genes coding for glutathione synthesis compared to the Col- $0 \mathrm{wt}$, confirms the results of the chemogenetic screening with yeast mutants and again highlights the central role of cellular GSH in the resistance of cells to selenocyanates.
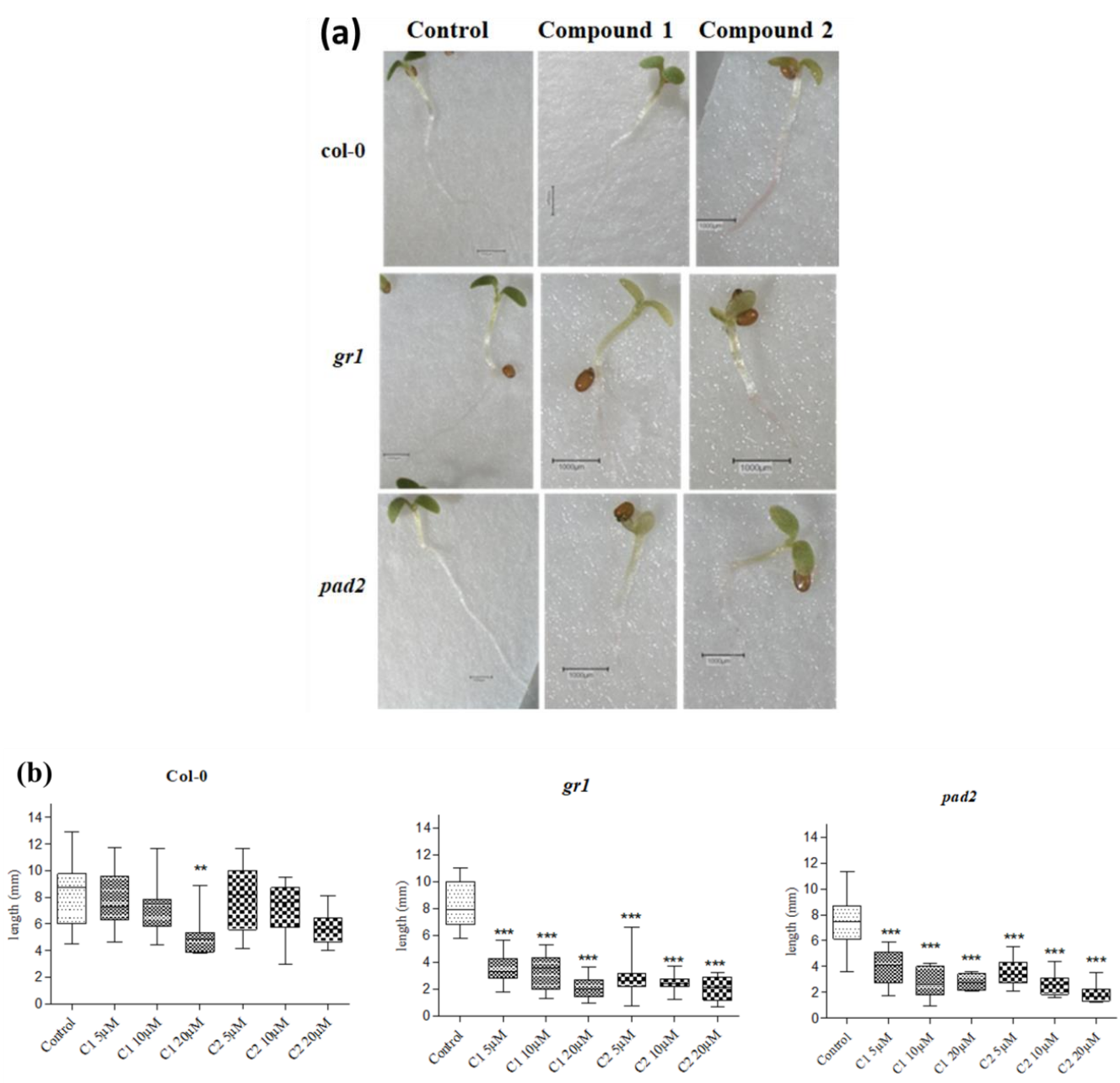

Figure 8. Effect of selenocyanates on Arabidopsis root growth. (a) Shows the phenotypes of Col-0 (wt), pad 2 and gr1 seedlings observed after three days of continual exposure to $20 \mu \mathrm{M}$ of selenocyanates in the growth medium. Scale bar $=1 \mathrm{~mm}$. (b) Shows the effect of continual exposure to 5, 10 and $20 \mu \mathrm{M}$ of selenocyanates on root growth of Col-0 (wt), pad 2 and gr1 seedlings. The box plots show the range of individual measurements, the mean \pm standard deviation, and the median value indicated as a horizontal line. C1-Compound 1 and C2-Compound 2. Values represent mean \pm S.D. ${ }^{* *} p<0.01$ and $* * * p<0.001$. 


\subsection{Glutathione Determination}

A standard glutathione reductase enzymatic recycling assay was carried out to determine the concentration of glutathione. Table 2 shows the concentration of glutathione in treated and untreated cells in two experiments. Untreated cells in two experiments were determined to have $1.730 \mathrm{mM}$ and $2.050 \mathrm{mM}$ of glutathione pooled, respectively. The cells treated with compound 1 were found to have $1.170 \mathrm{mM}$ and $1.176 \mathrm{mM}$ GSH, respectively, while sample treated with compound 2 contained $1.12 \mathrm{mM}$ and $1.15 \mathrm{mM}$ glutathione in two experiments. In each experiment, maximum and minimum values were determined by supposing either that a vacuole occupied $20 \%$ of the protoplast volume or a vacuole was absent from the cells. The treatment of yeast cells with selenocyanates resulted in the depletion of protective substance, glutathione, in comparison to untreated cells. These observations affirm the results of chemogenetic screening and Arabidopsis seedling root assay.

Table 2. Effects of treating BY4742 yeast cells with selenocyanates on the glutathione pool.

\begin{tabular}{ccccccc}
\hline & \multicolumn{3}{c}{ Experiment 1 } & Experiment 2 \\
\cline { 2 - 6 } & $\begin{array}{c}\text { Untreated } \\
\text { Cells }\end{array}$ & $\begin{array}{c}\text { Treated Cells } \\
\text { (Compound 1) }\end{array}$ & $\begin{array}{c}\text { Treated Cells } \\
\text { (Compound 2) }\end{array}$ & $\begin{array}{c}\text { Untreated } \\
\text { Cells }\end{array}$ & $\begin{array}{c}\text { Treated Cells } \\
\text { (Compound 1) }\end{array}$ & $\begin{array}{c}\text { Treated Cells } \\
\text { (Compound 2) }\end{array}$ \\
\hline $\begin{array}{c}\text { Total cellular conc. } \\
\text { of glutathione } \\
{[\mathrm{mM}]}\end{array}$ & $1.730 \pm 0.115$ & $1.170 \pm 0.020$ & $1.120 \pm 0.025$ & $2.050 \pm 0.130$ & $1.176 \pm 0.0530$ & $1.150 \pm 0.000$ \\
\hline
\end{tabular}

\section{Conclusions}

In summary, our studies with selected selenocyanates have provided a detailed insight into the mechanistic understanding of selenium-containing compounds. The focus of this investigation involved the exploration of the underlying mechanisms of the toxicity of selenium-containing compounds. The selected selenocyanates were evaluated against yeast in chemogenetic screening. Eleven yeast mutants were found hypersensitive in chemogenetc screening. Five mutants, YNL241C, YPL091W, YML007W, YGR209C and YHR183W, were deleted for genes responsible for glutathione synthesis and oxidative stress resistance proteins. Thus, these mutants share a common glutathione metabolic pathway. These mutants were studied further in detail by drop test, plate inhibition zone assay and streak test. These assays unraveled the greater inhibition of treated samples compared to untreated controls. The compound 2 exhibited excellent antifungal activity, almost completely inhibiting the growth of mutants. The central role of glutathione as a resistance mechanism against selenocyanates was also investigated in a higher multicellular organism, $A$. thaliana. The wildtype and glutathione deficient mutants of $A$. thaliana, pad2 and $g r 1$, were tested against specific concentrations of the selenocyanates. The decrease in the root length of mutants compared to $w t$, as well as untreated controls, confirmed the protective role of glutathione against selenocyanates. The hypersensitivity of $S$. cerevisiae and $A$. thaliana mutants suggests that selenocyanates may attack glutathione metabolism and glutathione pool in the target cells. In order to get further information into their putative mechanism of action, the glutathione concentration was measured in yeast cells treated with test compounds and in untreated samples. A correlation between selenocyanate treatment and a decrease in glutathione concentration was evident. These studies have also shown that these compounds target the glutathione pool and metabolism and cause an increase in oxidative stress. These findings also suggest the protective role of glutathione against test compounds. Subsequent studies are obviously needed to decipher the detailed mechanisms of selenium toxicity and the protective role of glutathione in decreased glutathione and increased oxidative stress conditions.

Supplementary Materials: The following are available online at http://www.mdpi.com/2076-3417/9/18/3728/s1, Table S1: List of Mutants.

Author Contributions: C.J. and M.C.H.G. conceived the study. M.S. and M.J.N. performed the experiments and analyzed the data. M.S. and M.C.H.G. wrote the manuscript.

Funding: This research received no external funding. 
Acknowledgments: Alan Slusarenko, Jana Reiter and Jan Borlinghaus are acknowledged for advice and discussions; and Ulrike Noll for help with editing and proof-reading the manuscript.

Conflicts of Interest: The authors declare no conflict of interest.

\section{References}

1. Jung, H.J.; Seo, Y.R. Current issues of selenium in cancer chemoprevention. Biofactors 2010, 36, 153-158. [CrossRef] [PubMed]

2. Weekley, C.M.; Harris, H.H. Which form is that? The importance of selenium speciation and metabolism in the prevention and treatment of disease. Chem. Soc. Rev. 2013, 42, 8870-8894. [CrossRef] [PubMed]

3. Anwar, A.; Gould, E.; Tinson, R.; Iqbal, J.; Hamilton, C. Redox Modulation at Work: Natural Phytoprotective Polysulfanes From Alliums Based on Redox-Active Sulfur. Curr. Pharm. Rep. 2018, 4, 397. [CrossRef]

4. Fry, F.H.; Holme, A.L.; Giles, N.M.; Giles, G.I.; Collins, C.; Holt, K.; Pariagh, S.; Gelbrich, T.; Hursthouse, M.B.; Gutowski, N.J.; et al. Multifunctional redox catalysts as selective enhancers of oxidative stress. Org. Biomol. Chem. 2005, 3, 2579-2587. [PubMed]

5. Gandin, V.; Fernandes, A.P. Organoselenium compounds as cancer therapeutic agents. In Organoselenium Compounds in Biology and Medicine: Synthesis, Biological and Therapeutic Treatments; Royal society of Chemistry: London, UK, 2018; pp. 401-435.

6. Nasim, M.J.; Ali, W.; Domínguez-Álvarez, E.; da Silva Júnior, E.N.; Saleem, R.S.Z.; Claus, J. Reactive selenium species: Redox modulation, antioxidant, antimicrobial and anticancer activities. In Organoselenium Compounds in Biology and Medicine: Synthesis, Biological and Therapeutic Treatments; The Royal Society of Chemistry: London, UK, 2018; pp. 277-302.

7. Du, P.; Viswanathan, U.M.; Xu, Z.; Ebrahimnejad, H.; Hanf, B.; Burkholz, T.; Schneider, M.; Bernhardt, I.; Kirsch, G.; Jacob, C. Synthesis of amphiphilic seleninic acid derivatives with considerable activity against cellular membranes and certain pathogenic microbes. J. Hazard. Mater. 2014, 269, 74-82. [CrossRef] [PubMed]

8. Nasim, M.J.; Witek, K.; Kincses, A.; Abdin, A.Y.; Zeslawska, E.; Marc, M.A.; Gajdács, M.; Spengler, G.; Nitek, W.; Latacz, G.; et al. Pronounced activity of aromatic selenocyanates against multidrug resistant ESKAPE bacteria. N. J. Chem. 2019, 43, 6021-6031. [CrossRef]

9. Sharma, A.; Sharma, A.K.; Madhunapantula, S.V.; Desai, D.; Huh, S.J.; Mosca, P.; Amin, S.; Robertson, G.P. Targeting Akt3 signaling in malignant melanoma using isoselenocyanates. Clin. Cancer Res. 2009, 15, 1674-1685. [CrossRef]

10. Crampsie, M.A.; Pandey, M.K.; Desai, D.; Spallholz, J.; Amin, S.; Sharma, A.K. Phenylalkyl isoselenocyanates vs phenylalkyl isothiocyanates: Thiol reactivity and its implications. Chem. Biol. Interact. 2012, 200, $28-37$. [CrossRef] [PubMed]

11. Bijlsma, M.F.; van Laarhoven, H.W. The conflicting roles of tumor stroma in pancreatic cancer and their contribution to the failure of clinical trials: A systematic review and critical appraisal. Cancer Metastasis Rev. 2015, 34, 97-114. [CrossRef] [PubMed]

12. Diaz, V.P.; Wolff, T.; Markovic, J.; Pallardo, F.V.; Foyer, C.H. A nuclear glutathione cycle within the cell cycle. Biochem. J. 2010, 431, 169-178.

13. Duan, S.; Chen, C. S-nitrosylation/denitrosylation and apoptosis of immune cells. Cell Mol. Immunol. 2007, 4, 353-358. [PubMed]

14. Selenius, M.; Hedman, M.; Brodin, D.; Gandin, V.; Rigobello, M.P.; Flygare, J.; Marzano, C.; Bindoli, A.; Brodin, O.; Bjornstedt, M.; et al. Effects of redox modulation by inhibition of thioredoxin reductase on radiosensitivity and gene expression. J. Cell Mol. Med. 2012, 16, 1593-1605. [CrossRef]

15. Hu, C.; Liu, M.; Zhang, W.; Xu, Q.; Ma, K.; Chen, L.; Wang, Z.; He, S.; Zhu, H.; Xu, N. Upregulation of KLF4 by methylseleninic acid in human esophageal squamous cell carcinoma cells: Modification of histone $\mathrm{H} 3$ acetylation through HAT/HDAC interplay. Mol. Carcinog. 2015, 54, 1051-1059. [CrossRef]

16. Rahib, L.; Smith, B.D.; Aizenberg, R.; Rosenzweig, A.B.; Fleshman, J.M.; Matrisian, L.M. Projecting cancer incidence and deaths to 2030: The unexpected burden of thyroid, liver, and pancreas cancers in the United States. Cancer Res. 2014, 74, 2913-2921. [CrossRef] [PubMed]

17. Jiang, C.; Wang, Z.; Ganther, H.; Lu, J. Distinct effects of methylseleninic acid versus selenite on apoptosis, cell cycle, and protein kinase pathways in DU145 human prostate cancer cells. Mol. Cancer 2002, 1, 1059-1066. 
18. Thirunavukkarasu, C.; Premkumar, K.; Sheriff, A.K.; Sakthisekaran, D. Sodium selenite enhances glutathione peroxidase activity and DNA strand breaks in hepatoma induced by N-nitrosodiethylamine and promoted by phenobarbital. Mol. Cell Biochem. 2008, 310, 129-139. [CrossRef] [PubMed]

19. Seitomer, E.; Balar, B.; He, D.; Copeland, P.R.; Kinzy, T.G. Analysis of Saccharomyces cerevisiae null allele strains identifies a larger role for DNA damage versus oxidative stress pathways in growth inhibition by selenium. Mol. Nutr. Food Res. 2008, 52, 1305-1315. [CrossRef]

20. De Miranda, J.X.; Andrade, F.O.; Conti, A.; Dagli, M.L.; Moreno, F.S.; Ong, T.P. Effects of selenium compounds on proliferation and epigenetic marks of breast cancer cells. J. Trace Elem. Med. Biol. 2014, 28, 486-491. [CrossRef]

21. Hughes, T.; Andrews, B.; Boone, C. Old drugs, new tricks: Using genetically sensitized yeast to reveal drug targets. Cell 2004, 116, 5-7. [CrossRef]

22. Giaever, G.; Shoemaker, D.D.; Jones, T.W.; Liang, H.; Winzeler, E.A.; Astromoff, A.; Davis, R.W. Genomic profiling of drug sensitivities via induced haploinsufficiency. Nat. Genet. 1999, 21, 278-283. [CrossRef]

23. Smith, A.M.; Ammar, R.; Nislow, C.; Giaever, G. A survey of yeast genomic assays for drug and target discovery. Pharmacol. Ther. 2010, 127, 156-164. [CrossRef]

24. Giaever, G.; Chu, A.M.; Ni, L.; Connelly, C.; Riles, L.; Veronneau, S.; Dow, S.; Lucau-Danila, A.; Anderson, K.; Andre, B.; et al. Functional profiling of the Saccharomyces cerevisiae genome. Nature 2002, 418, 387-391. [CrossRef]

25. Baldauf, S.L.; Palmer, J.D. Animals and fungi are each other's closest relatives: Congruent evidence from multiple proteins. Proc. Natl. Acad. Sci. USA 1993, 90, 11558-11562. [CrossRef]

26. Cross, F.R.; Buchler, N.E.; Skotheim, J.M. Evolution of networks and sequences in eukaryotic cell cycle control. Philos. Trans. R. Soc. Lond. B Biol. Sci. 2011, 366, 3532-3544. [CrossRef]

27. Botstein, D.; Chervitz, S.A.; Cherry, J.M. Yeast as a model organism. Science 1997, 277, 1259-1260. [CrossRef]

28. Botstein, D.; Fink, G.R. Yeast: An experimental organism for 21st Century biology. Genetics 2011, 189, 695-704. [CrossRef]

29. Leontiev, R.; Slusarenko, A.J. Finding the starting point for mode-of-action studies of novel selenium compounds: Yeast as a genetic toolkit. Curr. Org. Synth. 2017, 14, 1102-1108. [CrossRef]

30. Leontiev, R.; Hohaus, N.; Jacob, C.; Gruhlke, M.C.H.; Slusarenko, A.J. A Comparison of the Antibacterial and Antifungal Activities of Thiosulfinate Analogues of Allicin. Sci. Rep. 2018, 8, 6763. [CrossRef]

31. Griffith, O.W. Determination of glutathione and glutathione disulfide using glutathione reductase and 2-vinylpyridine. Anal. Biochem. 1980, 106, 207-212. [CrossRef]

32. Anderson, M.E. Determination of glutathione and glutathione disulfide in biological samples. Methods Enzym. 1985, 113, 548-555.

33. Walker, G.M. Yeast Physiology and Biotechnology; John Wiley \& Sons: Chichester, UK, 1998.

34. Baetz, K.; McHardy, L.; Gable, K.; Tarling, T.; Reberioux, D.; Bryan, J.; Andersen, R.J.; Dunn, T.; Hieter, P.; Roberge, M. Yeast genome-wide drug-induced haploinsufficiency screen to determine drug mode of action. Proc. Natl. Acad. Sci. USA 2004, 101, 4525-4530. [CrossRef]

35. Botet, J.; Rodriguez-Mateos, M.; Ballesta, J.P.; Revuelta, J.L.; Remacha, M. A chemical genomic screen in Saccharomyces cerevisiae reveals a role for diphthamidation of translation elongation factor 2 in inhibition of protein synthesis by sordarin. Antimicrob. Agents Chemother 2008, 52, 1623-1629. [CrossRef]

36. Deutschbauer, A.M.; Jaramillo, D.F.; Proctor, M.; Kumm, J.; Hillenmeyer, M.E.; Davis, R.W.; Nislow, C.; Giaever, G. Mechanisms of haploinsufficiency revealed by genome-wide profiling in yeast. Genetics 2005, 169, 1915-1925. [CrossRef]

37. Morano, K.A.; Grant, C.M.; Moye-Rowley, W.S. The response to heat shock and oxidative stress in Saccharomyces cerevisiae. Genetics 2012, 190, 1157-1195. [CrossRef]

38. Gruhlke, M.C.H.; Schlembach, I.; Leontiev, R.; Uebachs, A.; Gollwitzer, P.U.G.; Weiss, A.; Delaunay, A.; Toledano, M.; Slusarenko, A.J. Yap1p, the central regulator of the S. cerevisiae oxidative stress response, is activated by allicin, a natural oxidant and defence substance of garlic. Free Radic. Biol. Med. 2017, 108, 793-802. [CrossRef]

39. Lee, J.; Godon, C.; Lagniel, G.; Spector, D.; Garin, J.; Labarre, J.; Toledano, M.B. Yap1 and Skn7 control two specialized oxidative stress response regulons in yeast. J. Biol. Chem. 1999, 274, 16040-16046. [CrossRef]

40. Gruhlke, M.C.; Slusarenko, A.J. The biology of reactive sulfur species (RSS). Plant Physiol. Biochem. 2012, 59, 98-107. [CrossRef] 
41. Ankri, S.; Mirelman, D. Antimicrobial properties of allicin from garlic. Microbes Infect. 1999, 1, $125-129$. [CrossRef]

42. Müller, A.; Eller, J.; Albrecht, F.; Prochnow, P.; Kuhlmann, K.; Bandow, J.E.; Slusarenko, A.J.; Leichert, L.I. Allicin Induces Thiol Stress in Bacteria through S-Allylmercapto Modification of Protein Cysteines. J. Biol. Chem. 2016, 291, 11477-11490. [CrossRef]

43. Outten, C.E.; Culotta, V.C. A novel NADH kinase is the mitochondrial source of NADPH in Saccharomyces cerevisiae. EMBO J. 2003, 22, 2015-2024. [CrossRef]

44. Lopez-Mirabal, H.R.; Thorsen, M.; Kielland-Brandt, M.C.; Toledano, M.B.; Winther, J.R. Cytoplasmic glutathione redox status determines survival upon exposure to the thiol-oxidant 4,4'-dipyridyl disulfide. Fems Yeast Res. 2007, 7, 391-403. [CrossRef]

45. Temple, M.D.; Perrone, G.G.; Dawes, I.W. Complex cellular responses to reactive oxygen species. Trends Cell Biol. 2005, 15, 319-326. [CrossRef]

46. Gulshan, K.; Rovinsky, S.A.; Coleman, S.T.; Moye-Rowley, W.S. Oxidant-specific folding of Yap1p regulates both transcriptional activation and nuclear localization. J. Biol. Chem. 2005, 280, 40524-40533. [CrossRef]

47. Kuge, S.; Jones, N.; Nomoto, A. Regulation of yAP-1 nuclear localization in response to oxidative stress. EMBO J. 1997, 16, 1710-1720. [CrossRef]

48. Yan, C.; Lee, L.H.; Davis, L.I. Crm1p mediates regulated nuclear export of a yeast AP-1-like transcription factor. EMBO J. 1998, 17, 7416-7429. [CrossRef]

49. Delaunay, A.; Isnard, A.D.; Toledano, M.B. $\mathrm{H}_{2} \mathrm{O}_{2}$ sensing through oxidation of the Yap1 transcription factor. EMBO J. 2000, 19, 5157-5166. [CrossRef]

50. Ahmad, KA.; Clement, M.V.; Pervaiz, S. Pro-oxidant activity of low doses of resveratrol inhibits hydrogen peroxide-induced apoptosis. Ann. N. Y. Acad. Sci. 2003, 1010, 365-373. [CrossRef]

51. Escote, X.; Miranda, M.; Menoyo, S.; Rodriguez-Porrata, B.; Carmona-Gutierrez, D.; Jungwirth, H.; Madeo, F.; Cordero, R.R.; Mas, A.; Tinahones, F.; et al. Resveratrol induces antioxidant defence via transcription factor Yap1p. Yeast 2012, 29, 251-263. [CrossRef]

52. Vernoux, T.; Wilson, R.C.; Seeley, K.A.; Reichheld, J.P.; Muroy, S.; Brown, S.; Maughan, S.C.; Cobbett, C.S.; Van, M.M.; Inze, D.; et al. The ROOT MERISTEMLESS1/CADMIUM SENSITIVE2 gene defines a glutathione-dependent pathway involved in initiation and maintenance of cell division during postembryonic root development. Plant Cell 2000, 12, 97-110. [CrossRef]

53. Parisy, V.; Poinssot, B.; Owsianowski, L.; Buchala, A.; Glazebrook, J.; Mauch, F. Identification of PAD2 as a gamma-glutamylcysteine synthetase highlights the importance of glutathione in disease resistance of Arabidopsis. Plant. J. 2007, 49, 159-172. [CrossRef]

54. Mhamdi, A.; Hager, J.; Chaouch, S.; Queval, G.; Han, Y.; Taconnat, L.; Saindrenan, P.; Gouia, H.; Issakidis-Bourguet, E.; Renou, J.P.; et al. Arabidopsis GLUTATHIONE REDUCTASE1 plays a crucial role in leaf responses to intracellular hydrogen peroxide and in ensuring appropriate gene expression through both salicylic acid and jasmonic acid signaling pathways. Plant Physiol. 2010, 153, 1144-1160. [CrossRef] [PubMed]

(C) 2019 by the authors. Licensee MDPI, Basel, Switzerland. This article is an open access article distributed under the terms and conditions of the Creative Commons Attribution (CC BY) license (http://creativecommons.org/licenses/by/4.0/). 